stimulate the members in their endeavours to promote the interests of their branches of medicine in the widest sense.

It is generally conceded that the work already accomplished by the Council of British Ophthalmologists has fulfilled the expectations of its founders, and has more than justified its formation. We shall probably be safe in prophesying that a few years hence the American National Council will possess an equally commendable record.

\title{
Optical Benefits
}

The daily Press has recently drawn attention to the autocratic way in which the Ministry of Health administered the National Health Insurance Act, in so far that the permanent officials are able to impose penalties on panel practitioners. It seems also that they are able to alter the statutory rules and orders of this Act. Under the Additional Benefits Regulations, 1921, the payment of the whole or part of the cost of optical treatment and appliances was only to be made on the production of a prescription by a qualified practitioner or a hospital, except in cases where a claim is in respect of the renewal of an appliance. In other words according to this schedule no payment should be made by a society for the cost of spectacles, unless they have been prescribed by a medical man. The Ministry of Health have taken upon themselves not to insist upon the prescription of a medical man where the Insurance Society does not desire it. The result is that the diagnosis of the defects of vision is largely placed in the hands of opticians, who administer the optical benefits for the approved societies. It is hardly necessary for us to say that such optical treatment cannot be safely undertaken without a full knowledge of diseases of the eye, and the administration of ophthalmic benefits by most of the approved societies as now carried out is fraught with danger to the public, not only with regard to their eyesight but even in some cases to life.

It is to be hoped that the Royal Commission which is shortly going to report on the National Insurance Act will take cognisance of this anomaly, and will take into consideration the report which has been issued on sight-testing opticians by the Council of British Ophthalmologists (Vol. VI, 1922), and the recommendations of the Departmental Committee on the "Causes and Prevention of Blindness," 1922. 